\title{
The luminescence properties of rare-earth ions in natural fluorite
}

\author{
M. Czaja $\cdot$ S. Bodył-Gajowska $\cdot$ R. Lisiecki $\cdot$ \\ A. Meijerink $\cdot$ Z. Mazurak
}

Received: 18 June 2011/ Accepted: 2 June 2012/Published online: 23 June 2012

(C) The Author(s) 2012. This article is published with open access at Springerlink.com

\begin{abstract}
For the first time, the luminescence properties of $\mathrm{Pr}^{3+}, \mathrm{Nd}^{3+}$ and $\mathrm{Tm}^{3+}$ and $\mathrm{Yb}^{3+}$ ions in fluorite crystal have been obtained by steady-state measurements. In addition, the luminescence spectra of $\mathrm{Ce}^{3+}, \mathrm{Sm}^{2+}, \mathrm{Sm}^{3+}$, $\mathrm{Dy}^{3+}, \mathrm{Er}^{3+}$ and $\mathrm{Yb}^{3+}$ were measured. It was pointed out that $\lambda_{\text {exc. }}=415 \mathrm{~nm}$ is most suitable for measuring the $\mathrm{Ho}^{3+}$ emission beside the $\mathrm{Er}^{3+}$. The emission of trivalent holmium and erbium ions was measured independently using time-resolved measurements and tentative assignment of luminescence lines to $C_{3 v}$ and $C_{4 v}$ symmetry sites was proposed. Besides for natural fluorite crystal, the transitions between Stark energy levels of lanthanide ions were presented.
\end{abstract}

Keywords Photoluminescence · Fluorite ·

Rare-earth ions $\cdot$ Stark energy levels

M. Czaja $(\bowtie) \cdot$ S. Bodył-Gajowska

Faculty of Earth Sciences, University of Silesia, ul. Będzińska 60, 41-200, Sosnowiec, Poland

e-mail: maria.czaja@us.edu.pl

R. Lisiecki

Institute of Low Temperature and Structure Research,

Polish Academy of Sciences, Okólna 2, 50-422 Wrocław, Poland

A. Meijerink

Debye Institute, Ornstein Laboratory, University of Utrecht,

Princetonplein 1, Utrecht, The Netherlands

\section{Z. Mazurak}

Center of Polymer and Carbon Materials,

Polish Academy of Sciences, M. Skłodowskiej-Curie 34,

41-819 Zabrze, Poland

\section{Introduction}

Fluorite is one of the best-known fluorescent minerals, and its specific properties led G. Stokes to name this phenomenon "fluorescence". The luminescence of natural fluorite crystals was measured by various methods, among which the photoluminescence (PL) was most often used and significant. The luminescence of fluorite is connected mainly to the presence of rare-earth ions in it. The electrostatic stability of $\mathrm{CaF}_{2}$ lattice in presence of $\mathrm{RE}^{3+}$ ions demands the additional negative charge, mainly as an $\mathrm{F}^{-}$ion in interstitial sites. The effective symmetry around rare-earth ions could be $O_{h}$ (for $\mathrm{Pr}^{3+}, \mathrm{Nd}^{3+}, \mathrm{Sm}^{3+}, \mathrm{Eu}^{3+}, \mathrm{Gd}^{3+}, \mathrm{Tb}^{3+}, \mathrm{Dy}^{3+}, \mathrm{Er}^{3+}$ and $\mathrm{Yb}^{3+}$ ions), $C_{3 v}$ (for $\mathrm{Gd}^{3+}, \mathrm{Tb}^{3+}, \mathrm{Dy}^{3+}, \mathrm{Ho}^{3+}, \mathrm{Er}^{3+}$ and $\mathrm{Yb}^{3+}$ ions) or $C_{4 v}$ (for $\mathrm{Ce}^{3+}, \mathrm{Nd}^{3+}, \mathrm{Gd}^{3+}, \mathrm{Tb}^{3+}, \mathrm{Dy}^{3+}, \mathrm{Ho}^{3+}, \mathrm{Er}^{3+}$ and $\mathrm{Yb}^{3+}$ ions), what was confirmed by EPR measurements (Weber and Bierig 1964). There has been a large number of research papers on the luminescence of natural fluorite measured by the steady-state method (Illiev et al. 1988; Aierken et al. 2000, 2003; Bodył 2006; Petit et al. 2007; Czaja et al. 2008; Bodył 2009) or the time-resolved method (Gaft et al. 1998, 2001a, b, 2005, 2008). Moreover, the synthetic $\mathrm{CaF}_{2}, \mathrm{BaF}_{2}$ and $\mathrm{SrF}_{2}$ crystals doped with $\mathrm{RE}$ ions were investigated intensively (Wood and Kaiser 1962; Kirilyuk 1973; Fenn et al. 1973; Tallant and Wright 1975; Seelbinder and Wright 1979; Chrysochoos et al. 1982, 1983; Illiev et al. 1988; Caldino et al. 1989; Oskam et al. 2002). The splitting of ground and excited levels of $\mathrm{Gd}^{3+}, \mathrm{Er}^{3+}$ and $\mathrm{Ho}^{3+}$ ions were determined, and luminescence lines were assigned to the $C_{4 v}$ and $C_{3 v}$ symmetry sites on the basis of EPR and electronic optical measurements (Rector et al. 1966; Tallant and Wright 1975; Seelbinder and Wright 1979; Mujaji et al. 1992). In the case of heavy-doped $\mathrm{CaF}_{2}$ synthetic crystals and their analogues, other luminescence centers, such as pairs or clusters, have been discussed by 
researchers, too (Fenn et al. 1973; Seelbinder and Wright 1979).

In this paper, we have demonstrated the possibility of steady-state photoluminescence measurement for the purpose of identification of $4 f$ ions using the mutual relationship between excitation and emission spectra. For the first time ever, the emission and excitation spectra of $\mathrm{Pr}^{3+}$, $\mathrm{Nd}^{3+}, \mathrm{Tm}^{3+}$ and $\mathrm{Yb}^{3+}$ in natural fluorite crystal were investigated by this method. Moreover, we have proposed the most effective excitation for holmium ion emission. Furthermore, the tentative assignment emission line to the respective transition in $C_{3 v}$ and $C_{4 v}$ symmetry sites was made from the time-resolved spectra of $\mathrm{Er}^{3+}$ and $\mathrm{Ho}^{3+}$ ions.

\section{Sample properties and measurement conditions}

The fluorite crystals studied in this work were found in a lens-like biotite-hornblendite pegmatite in Paszowice (Sudety Mountains, Poland). These crystals were transparent and pale yellow, but rather small $\left(1 \mathrm{~mm}^{3}\right)$. The crystal phase was confirmed by X-ray diffraction (Philips PW 3710). The amount of lanthanides was measured by the ICP-MS method in ACME Laboratory (Canada). The marked europium anomaly (0.004) and the plot of REE (rare-earth element) content normalized to chondrite $\mathrm{C} 1$ (Fig. 1) are typical for pegmatite fluorite. The

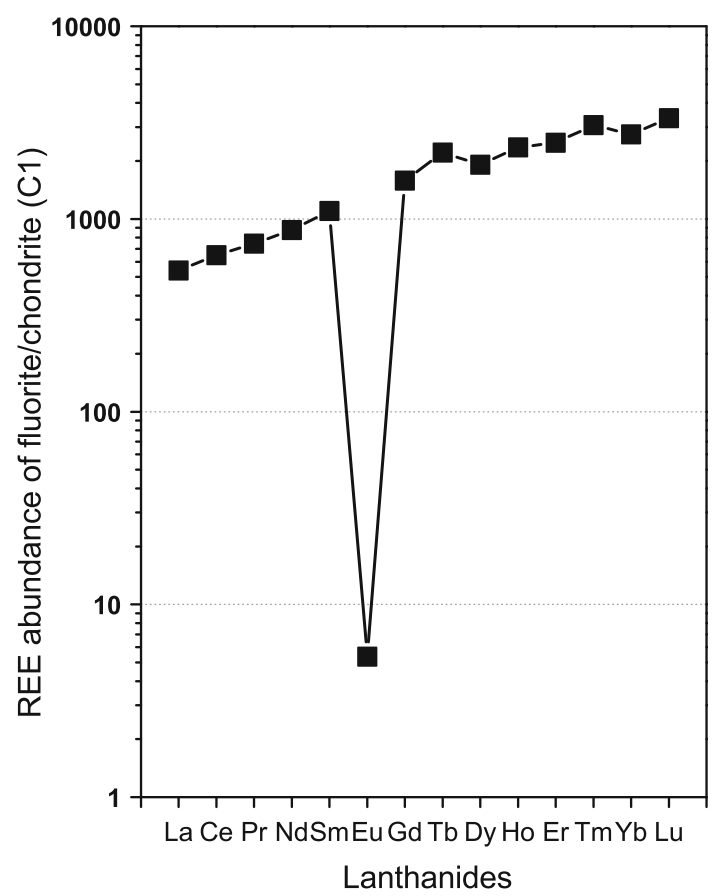

Fig. 1 REE content in fluorite (Paszowice, Poland) normalized to chondrite $\mathrm{C} 1$
$\Sigma$ REE $=15,765.68 \mathrm{ppm}, \quad \Sigma$ HREE $=14,588.79 \mathrm{ppm}$ and $\Sigma$ HREE $/ \Sigma$ LREE $=12.4$, where LREE-light rare-earth element, i.e., La-Eu, HREE-hard rare-earth element), i.e., $\mathrm{Gd}-\mathrm{Lu}$ and $\mathrm{Y}$ ). However, when the $\mathrm{Y}$ is excluded, the contents of light, medium and heavy REE are similar.

To find the most convenient conditions to measure $\mathrm{Ho}^{3+}$ luminescence in the presence of $\mathrm{Er}^{3+}$ ions, the luminescence spectra of phosphate glass doped by holmium and erbium: $44 \% \mathrm{P}_{2} \mathrm{O}_{5}+25 \% \mathrm{CaO}+15 \% \mathrm{BaO}+15 \%$ $\mathrm{SrO}+1 \% \quad \mathrm{Ho}_{2} \mathrm{O}_{3}, 44 \% \mathrm{P}_{2} \mathrm{O}_{5}+25 \% \mathrm{CaO}+15 \%$ $\mathrm{BaO}+15 \% \mathrm{SrO}+1 \% \mathrm{Er}_{2} \mathrm{O}_{3}$ were synthesized.

Phosphate glasses doped with lanthanide ion or ions can be easily synthesized-easier than $\mathrm{CaF}_{2}$ crystals. However, the optical properties of $4 \mathrm{f}$ ions in these glasses, especially $\Omega_{\mathrm{i}}$ parameters, are different from those in other host materials, although the positions of emission and excitation bands can be treated as a standard (with accuracy measured in $\pm \mathrm{nm}$ ) in order to identify each particular $4 \mathrm{f}$ ion. We have observed that it is especially useful for $\mathrm{Pr}^{3+}-\mathrm{Sm}^{3+}$ ions in apatite crystals (Bodył et al. 2009) and for $\mathrm{Er}^{3+}-\mathrm{Ho}^{3+}$ ions in fluorite and scheelite crystals (Czaja et al. 2008). To enhance the emission of $\mathrm{Ho}^{3+}$ ions in the presence of $\mathrm{Er}^{3+}$ ions in the spectral range of $550 \mathrm{~nm}$, a $415 \mathrm{~nm}$ excitation was chosen. For this excitation, the transition ${ }^{5} \mathrm{I}_{8} \rightarrow{ }^{5} \mathrm{G}_{5}$ of $\mathrm{Ho}^{3+}$ ions can be observed besides the transition ${ }^{4} \mathrm{I}_{15 / 2} \rightarrow{ }^{2} \mathrm{H}_{9 / 2}$ of $\mathrm{Er}^{3+}$ ions. However, the emission from the ${ }^{2} \mathrm{H}_{9 / 2}$ level was not measured, in contrast to the emission from ${ }^{4} \mathrm{~S}_{3 / 2}$.

The steady-state fluorescence measurements for $\mathrm{Ce}^{3+}$, $\mathrm{Pr}^{3+}, \mathrm{Sm}^{3+}, \mathrm{Eu}^{2+}, \mathrm{Tb}^{3+}, \mathrm{Dy}^{3+}, \mathrm{Ho}^{3+}, \mathrm{Er}^{3+}$ and $\mathrm{Tm}^{3+}$ were performed using a Jobin-Yvon (SPEX) spectrofluorimeter FLUORLOG 3-12 at room and low temperatures using a $450 \mathrm{~W}$ xenon lamp, a double-grating monochromator, and a Hamamatsu 928 photomultiplier. Other steady-time measurements were done for $\mathrm{Nd}^{3+}, \mathrm{Sm}^{2+}$, $\mathrm{Er}^{3+}$ and $\mathrm{Yb}^{3+}$ using an Edinburgh Instruments FLS920 spectrofluorimeter with a xenon lamp and Hamamatsu 928 or Hamamatsu R5509-72 photomultipliers or Physik LPD3000 laser (pumped by a Lambda Physik LPX100 excimer laser). The time-resolved emission spectra and decay times were measured using a GDM-1000 doublegrating monochromator, equipped with a Hamamatsu 928 photomultiplier. The resulting luminescence signal was stored in a Stanford model SRS 250 Boxcar Integrator coupled with a PC computer. The emission-line accuracy was $0.1 \mathrm{~nm}$. Because the sensitivity of the Hamamatsu 928 or Hamamatsu R5509-72 photomultipliers is almost constant in the range $400-700 \mathrm{~nm}$, no correction curve was needed.

The luminescence decay curves were excited by applying a short impulsive light from an OPO Optical Parametrical Oscillator pumped by the third-harmonic of a YAG:Nd laser. The decay kinetics of excited states were 
recorded utilizing a Tektronix model TDS 3052 digital oscilloscope. The decay time and gate width were chosen according to the decay time of each expected luminescence center.

\section{Results and discussion}

Steady-state measurements for $4 f-5 d$ transitions

The luminescence spectrum of $\mathrm{Ce}^{3+}$ ion of the studied fluorite was very similar to those which were known from Aierken et al. (2000) or Bodył (2009). For $\lambda_{\text {exc. }}=302 \mathrm{~nm}$, the intensive bands at 320 and 343 (336) nm, called by Aierken et al. (2000) A and B, were measured and could be assigned to the transitions from $5 d\left(\mathrm{E}_{\mathrm{g}}\right) \rightarrow 4 f\left({ }^{2} \mathrm{~F}_{5 / 2}\right)$ and $4 f\left({ }^{2} \mathrm{~F}_{7 / 2}\right)$, respectively. The $\mathrm{Eu}^{2+}$ ions usually caused a very characteristic blue emission, which was usually measured at $420 \mathrm{~nm}$ as the electronic transition $4 f^{6} 5 d\left(\mathrm{E}_{\mathrm{g}}\right) \rightarrow 4 f^{7}\left({ }^{8} \mathrm{~S}_{7 / 2}\right)$. However, for this crystal, the said emission was not measured, due to a very low Eu concentration (Table 1).

The emission of $\mathrm{Sm}^{2+}$ ions was measured at low temperatures (Fig. 2). In fluorite, the excited $4 f^{6}$ level $\left({ }^{5} \mathrm{D}_{0}\right)$ is just below the lowest excited $4 f^{5} 5 d\left(\mathrm{E}_{\mathrm{g}}\right)$ level (Wood and Kaiser 1962), so the energy of the lowest level of te $4 f^{5}-5 d^{1}$ excited electronic configuration could interact significantly with the ${ }^{5} \mathrm{D}_{\mathrm{j}}$ levels of the $4 f$ ground configuration and have a strong influence on the optical properties of $\mathrm{Sm}^{2+}$. The sharp and intensive emission line at $683 \mathrm{~nm}\left(14,641 \mathrm{~cm}^{-1}\right)$ could be attributed to the zero-phonon line (ZPL) of the $\mathrm{T}_{1 \mathrm{u}}\left(4 f^{5} 5 d\right) \rightarrow \mathrm{A}_{1 \mathrm{~g}}\left({ }^{7} \mathrm{~F}_{0}\left(4 f^{6}\right)\right)$ transition. Other emission lines at the longer wavelength part of the spectrum, that is, $693 \mathrm{~nm} \quad\left(14,430 \mathrm{~cm}^{-1}\right), \quad 697 \mathrm{~nm} \quad\left(14,347 \mathrm{~cm}^{-1}\right)$ and $699 \mathrm{~nm}\left(14,306 \mathrm{~cm}^{-1}\right)$, have a vibronic origin according to the Elcombe and Pryor (1970) and correspond to the ZPL minus the frequency of modes 210,250 and $355 \mathrm{~cm}^{-1}$, respectively. The emission lines at 708, 720, 730, 748, 761 and $793 \mathrm{~nm}$ are assigned to the ${ }^{5} \mathrm{D}_{0} \rightarrow{ }^{7} \mathrm{~F}_{\mathrm{J}}(\mathrm{J}=0,1, \ldots, 6)$, and the $365,452,467,485$ and $494 \mathrm{~nm}$ lines on the excitation spectrum to the $4 f^{6}\left({ }^{7} \mathrm{~F}_{0}\right) \rightarrow 4 f^{5}\left({ }^{6} \mathrm{~F}_{\mathrm{j}}\right.$ and $\left.{ }^{6} \mathrm{H}_{\mathrm{j}}\right) 5 d\left(\mathrm{~T}_{2 \mathrm{~g}}\right)$ transitions, respectively.

Steady-state measurements for $4 f-4 f$ transitions

Neodymium $\left(\mathrm{Nd}^{3+}\right)$ is one of the most efficient RE centers in minerals, and its characteristic spin-allowed transitions in

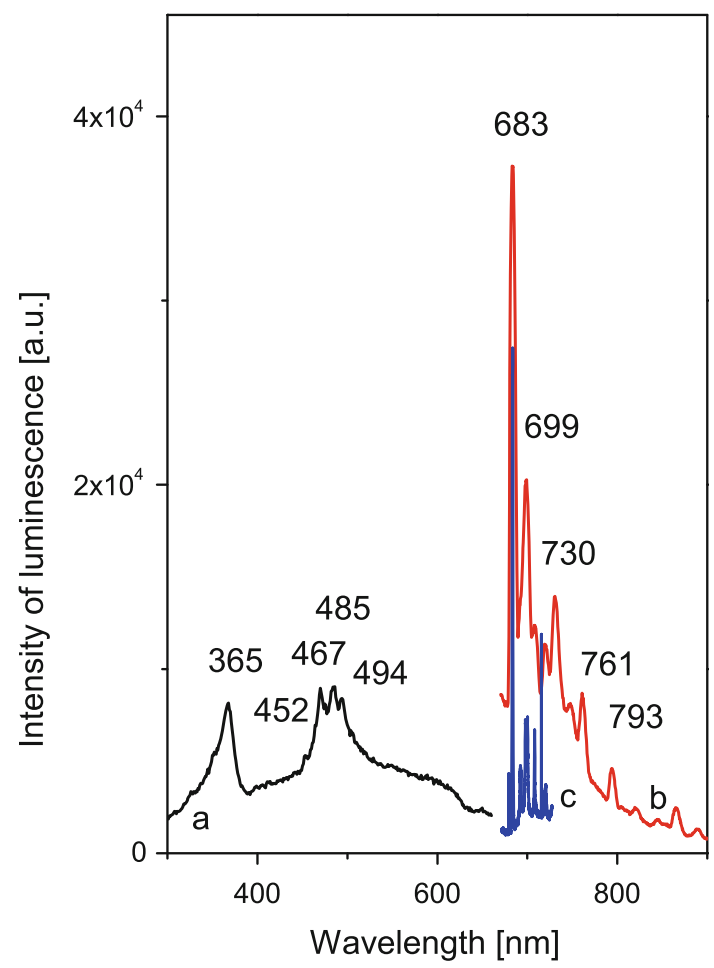

Fig. 2 Luminescence spectra of $\mathrm{Sm}^{2+}: a$ excitation spectrum monitored at $\lambda_{\mathrm{em}}=682 \mathrm{~nm}$ at $\mathrm{T}=6 \mathrm{~K}$ (black line), $b$ and $c$ emission spectra measured at $\lambda_{\text {exc. }}=485 \mathrm{~nm}$ at $\mathrm{T}=100 \mathrm{~K}$ and $\mathrm{T}=6 \mathrm{~K}$, as red and blue lines, respectively

NIR range are ${ }^{4} \mathrm{~F}_{3 / 2} \rightarrow{ }^{4} \mathrm{I}_{9 / 2}(864$ and $895 \mathrm{~nm})$ and ${ }^{4} \mathrm{~F}_{3 / 2} \rightarrow$ ${ }^{4} \mathrm{I}_{11 / 2}(1,065 \mathrm{~nm})$. The NIR emission spectra of $\mathrm{Nd}^{3+}$ ion in minerals were measured so far by the time-resolved technique. The steady-state luminescence spectrum of $\mathrm{Nd}^{3+}$ ions in our fluorite crystal was measured and presented on Fig. 3. The decay time of the ${ }^{4} \mathrm{~F}_{3 / 2}$ state of $\mathrm{Nd}^{3+}$ ions in this fluorite had the value of $\tau=635 \mu$ s. A similarly long decay time of this transition was earlier found in $\mathrm{Cs}_{2} \mathrm{NaNdCl}_{6}$ $\left[\rho(\mathrm{Nd})=3.2 \times 10^{21} \mathrm{~cm}^{-3}\right]$ and in $\mathrm{Cs}_{2} \mathrm{NaNd}_{0.01} \mathrm{Y}_{0.99} \mathrm{Cl}_{6}$ crystals (Tofield and Weber 1974) and it amounted to 1.23 and $4.1 \mathrm{~ms}$, respectively. This means that $\mathrm{Nd}^{3+}$ ions in our fluorite crystal occupy the $O_{h}$ symmetry site because only strict octahedral coordination of $\mathrm{Nd}^{3+}$ discourages electricdipole electronic transitions. Subramanian and Mukherjee (1987) predicated that $\mathrm{Nd}^{3+}$ ions in fluorite could occupy the $O_{h}$ and $C_{4 v}$ sites.

Moreover, additional emission peaks of $\mathrm{Er}^{3+}$ at $1,529 \mathrm{~nm}\left({ }^{4} \mathrm{I}_{13 / 2} \rightarrow{ }^{4} \mathrm{I}_{15 / 2}\right)$ and $\mathrm{Er}^{3+}\left({ }^{4} \mathrm{I}_{11 / 2} \rightarrow{ }^{4} \mathrm{I}_{15 / 2}\right)$ together with $\mathrm{Yb}^{3}\left({ }^{4} \mathrm{~F}_{5 / 2} \rightarrow{ }^{2} \mathrm{~F}_{7 / 2}\right)$ at $978 \mathrm{~nm}$ were observed.

Table 1 Abundance (ppm) of rare-earth impurities in natural fluorite from Paszowice, compared with Aierken et al. (2003)

\begin{tabular}{|c|c|c|c|c|c|c|c|c|c|c|c|c|c|c|c|}
\hline Fluorite & $\mathrm{La}$ & $\mathrm{Ce}$ & $\operatorname{Pr}$ & $\mathrm{Nd}$ & $\mathrm{Sm}$ & $\mathrm{Eu}$ & $\mathrm{Gd}$ & $\mathrm{Tb}$ & Dy & Ho & $\mathrm{Er}$ & $\mathrm{Tm}$ & $\mathrm{Yb}$ & $\mathrm{Lu}$ & Y \\
\hline Paszowice & 142 & 400 & 69 & 401 & 164 & 0.3 & 312 & 79 & 468 & 129 & 398 & 76 & 437 & 82 & 12,609 \\
\hline luorite Aierken et al. (2003) & 270 & 670 & 119 & 678 & 469 & 1.1 & 255 & 237 & 1,349 & 312 & 927 & 137 & 1,010 & 141 & - \\
\hline
\end{tabular}




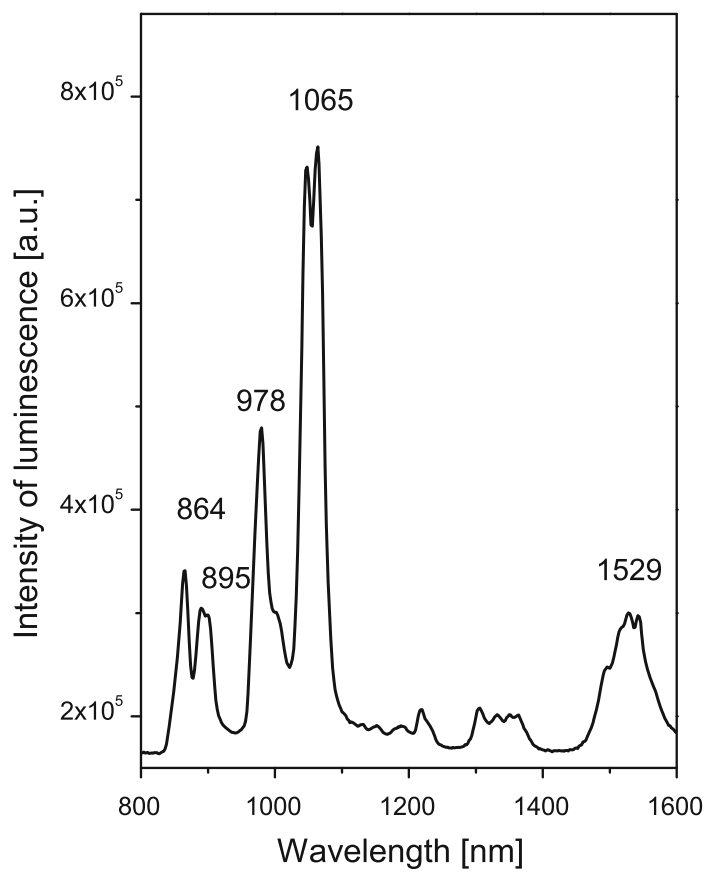

Fig. 3 Luminescence emission spectrum of $\mathrm{Nd}^{3+}, \mathrm{Yb}^{3+}$ and $\mathrm{Er}^{3+}$ measured for $\lambda_{\text {exc. }}=521 \mathrm{~nm}$, measured at T $=300 \mathrm{~K}$

The luminescence lifetime for ${ }^{4} \mathrm{~F}_{5 / 2}$ state of $\mathrm{Yb}^{3+}$ ion in this fluorite was measured and was equal to $\tau=9.3 \mathrm{~ms}$, which was coherent with the results obtained earlier. For the $\mathrm{Yb}^{3+}$ ion in $C_{4 v}$ site symmetry in synthetic $\mathrm{CaF}_{2}$, Petit et al. (2007) have observed that the luminescence lifetime was $\tau=8 \mathrm{~ms}$.

For the $\mathrm{Pr}^{3+}$ ion, the characteristic emission lines and corresponding transitions are 480-500 $\mathrm{nm}\left({ }^{3} \mathrm{P}_{0} \rightarrow{ }^{3} \mathrm{H}_{4}\right)$, $650-670 \mathrm{~nm} \quad\left({ }^{3} \mathrm{P}_{0} \rightarrow{ }^{3} \mathrm{~F}_{2}\right), \quad 750-770 \mathrm{~nm} \quad\left({ }^{3} \mathrm{P}_{0} \rightarrow{ }^{3} \mathrm{~F}_{4}\right)$, 610-630 nm $\left({ }^{1} \mathrm{D}_{2} \rightarrow{ }^{3} \mathrm{H}_{4}\right)$ and $\left({ }^{3} \mathrm{P}_{0} \rightarrow{ }^{3} \mathrm{H}_{6}\right), 400-410 \mathrm{~nm}$ $\left({ }^{1} \mathrm{~S}_{0} \rightarrow{ }^{1} \mathrm{I}_{6}\right)$. Likewise, some other transitions $(5 d-4 f)$ were measured in the UV region (Gaft et al. 2005). The steadystate luminescence measurements of $\mathrm{Pr}^{3+}$ in minerals are difficult because radiative transitions of this ion are hidden by the stronger emission of $\mathrm{Sm}^{3+}$ ion (600-650 nm), Dy ${ }^{3+}$ ion $(470-490 \mathrm{~nm})$ or $\mathrm{Nd}^{3+}$ in the IR range (870-900 nm) (Gaft et al. 2005). It has been noticed (Bodył et al. 2009) that the emission of the $\mathrm{Pr}^{3+}$ ion is most intensive for $\lambda_{\text {exc. }}=442 \mathrm{~nm}$. For such a condition (Fig. 4), the diagnostic emission lines connected to the ${ }^{3} \mathrm{P}_{0} \rightarrow{ }^{3} \mathrm{H}_{6}$ and ${ }^{3} \mathrm{P}_{0} \rightarrow{ }^{3} \mathrm{~F}_{2}$ transitions, appeared at 614 and $641 \mathrm{~nm}$, respectively. Other emission lines on this spectrum (598 and $607 \mathrm{~nm}$ ) could be assigned to the ${ }^{4} \mathrm{G}_{5 / 2} \rightarrow{ }^{6} \mathrm{H}_{7 / 2}$ transition of the $\mathrm{Sm}^{3+}$ ion. Chrysochoos et al. $(1982,1983)$ revealed that $\operatorname{Pr}^{3+}$ ions occupied mainly $O_{h}$ and $C_{4 v}$ positions.

The most efficient $\mathrm{Sm}^{3+}$ luminescence is usually measured for $\lambda_{\text {exc. }}=399-401 \mathrm{~nm}$ (Bodył et al. 2009). The luminescence spectra of our fluorite crystal (Fig. 5) have

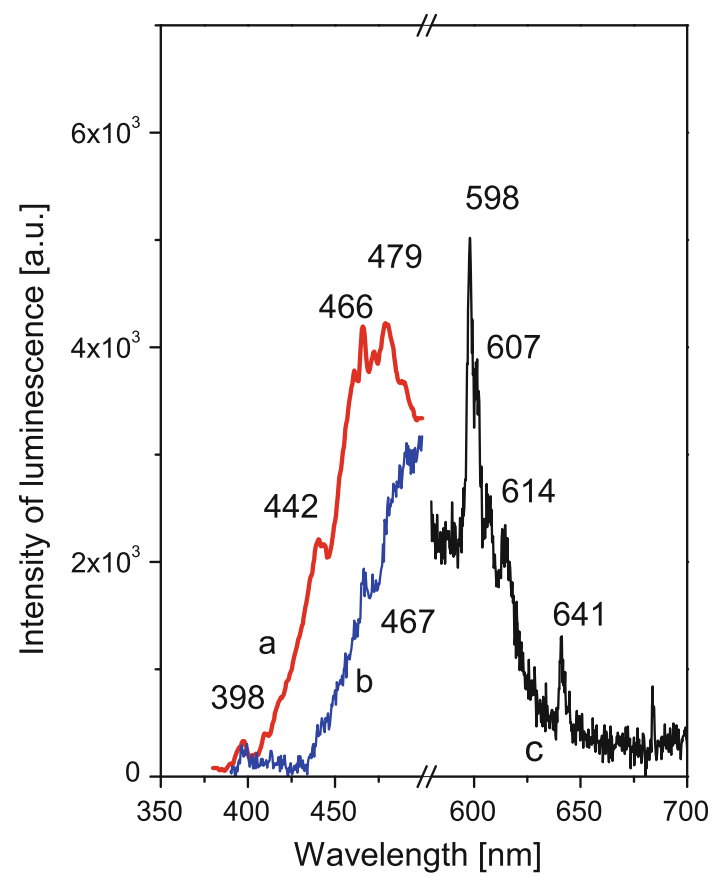

Fig. 4 Luminescence spectra of $\operatorname{Pr}^{3+}: a$ and $b$ excitation spectra monitored at 614 and $641 \mathrm{~nm}$, as red and blue lines, respectively, $c$ emission spectrum measured for $\lambda_{\text {exc. }}=442 \mathrm{~nm}$, measured at $\mathrm{T}=300 \mathrm{~K}$ (black line)

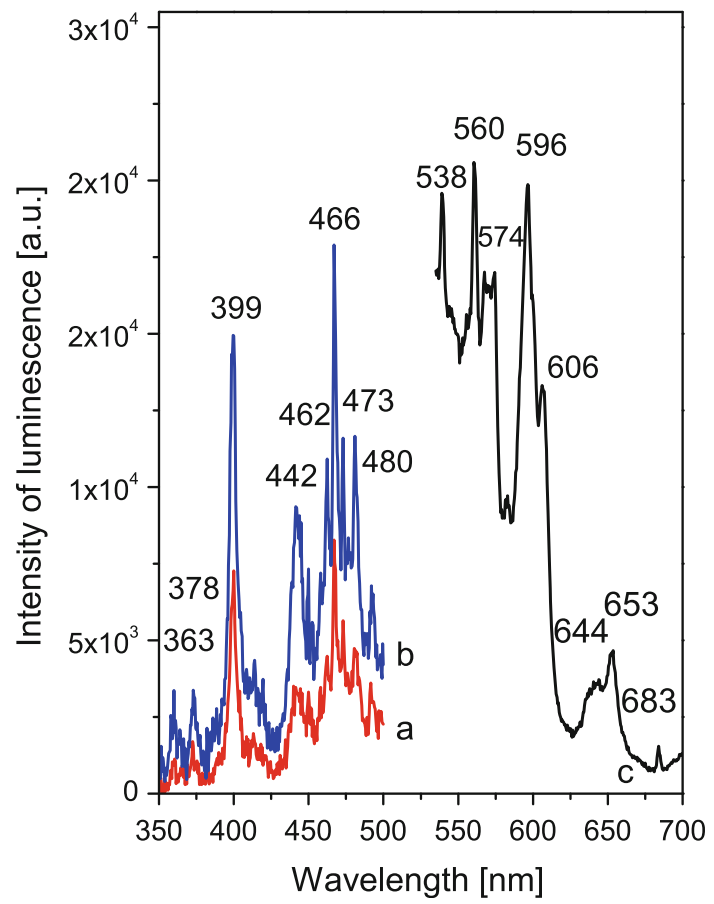

Fig. 5 Luminescence spectra of $\mathrm{Sm}^{3+}: a$ and $b$ excitation spectra monitored at $\lambda_{\mathrm{em}}=596$ and $606 \mathrm{~nm}$, as red and blue lines, respectively, $c$ emission spectrum measured for $\lambda_{\text {exc. }}=399 \mathrm{~nm}$, measured at $\mathrm{T}=300 \mathrm{~K}$ (black line) 


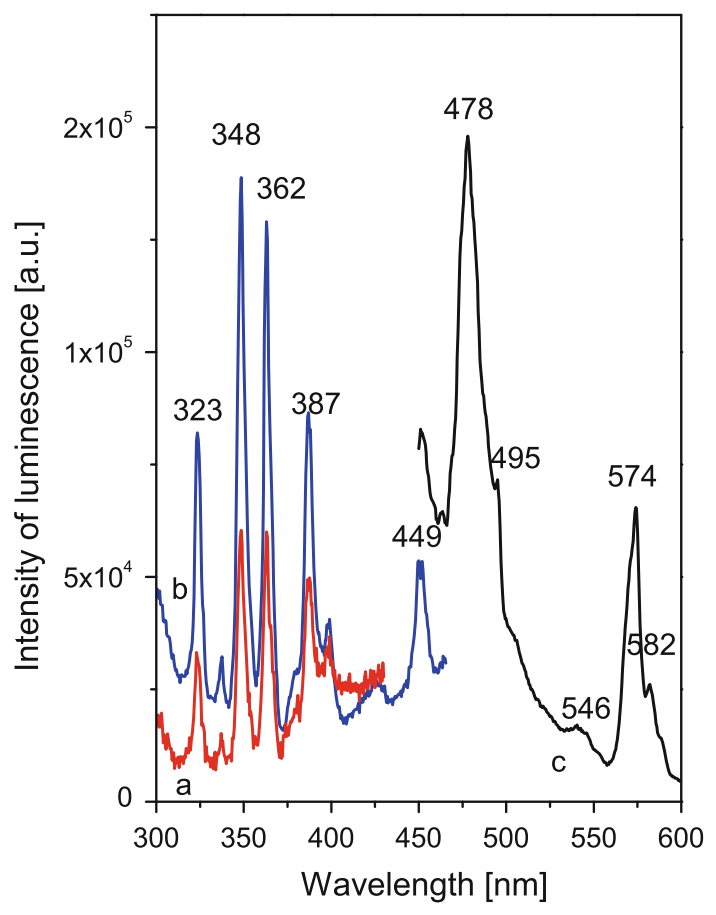

Fig. 6 Luminescence spectra of $\mathrm{Dy}^{3+}: a$ and $b$ excitation spectra monitored at $\lambda_{\mathrm{em}}=574$ and $478 \mathrm{~nm}$, as red and blue lines, respectively, $c$ emission spectrum for $\lambda_{\text {exc. }}=348 \mathrm{~nm}$, measured at $\mathrm{T}=300 \mathrm{~K}$ (black line)

seemed similar to those presented by Aierken et al. (2003). Besides the emission of $\mathrm{Sm}^{3+}: 560 \mathrm{~nm}\left({ }^{4} \mathrm{G}_{5 / 2} \rightarrow{ }^{6} \mathrm{H}_{5 / 2}\right)$, 599 and $606 \mathrm{~nm}\left({ }^{4} \mathrm{G}_{5 / 2} \rightarrow{ }^{6} \mathrm{H}_{7 / 2}\right)$ and 644 and $653 \mathrm{~nm}$ $\left({ }^{4} \mathrm{G}_{5 / 2} \rightarrow{ }^{6} \mathrm{H}_{9 / 2}\right)$, emission lines of Dy ${ }^{3+}$ at $574 \mathrm{~nm}\left({ }^{4} \mathrm{~F}_{9 / 2} \rightarrow\right.$ $\left.{ }^{6} \mathrm{H}_{13 / 2}\right), \mathrm{Er}^{3+}$ at $538 \mathrm{~nm}\left({ }^{4} \mathrm{~S}_{3 / 2} \rightarrow{ }^{4} \mathrm{I}_{15 / 2}\right)$ and at $653 \mathrm{~nm}$ $\left({ }^{4} \mathrm{~F}_{9 / 2} \rightarrow{ }^{4} \mathrm{I}_{15 / 2}\right)$, and $\mathrm{Sm}^{2+}$ at $683 \mathrm{~nm}\left(4 f^{5} 5 d \rightarrow 4 f^{6}\right)$ were observed as well.

It was established that the proper $\lambda_{\text {exc. }}$ for $\mathrm{Dy}^{3+}$ ion is equal $348 \mathrm{~nm}$. The emission lines at $478 \mathrm{~nm}\left({ }^{4} \mathrm{~F}_{9 / 2} \rightarrow\right.$ $\left.{ }^{6} \mathrm{H}_{15 / 2}\right)$ and $574 \mathrm{~nm}\left({ }^{4} \mathrm{~F}_{9 / 2} \rightarrow{ }^{6} \mathrm{H}_{13 / 2}\right)$ were measured (Fig. 6). When other excitation was used, the emission of another ion (or ions) was measured. For example, the emission of erbium ion $(542 \mathrm{~nm})$ besides dysprosium ion was measured for $\lambda_{\text {exc }}=323,362$ or $387 \mathrm{~nm}$, while an emission of $\mathrm{Sm}^{3+}$ and $\mathrm{Pr}^{3+}$ ions was observed for $\lambda_{\text {exc. }}=449 \mathrm{~nm}$. On the other hand, for $\lambda_{\text {exc. }}=348 \mathrm{~nm}$, Aierken et al. (2003) have shown the emissions of $\mathrm{Tb}^{3+}$ as peaks at 495, 546, 582 and $623 \mathrm{~nm}$. The first three of them were present on our fluorite spectrum (Fig. 6); however, no characteristic excitation lines of the $\mathrm{Tm}^{3+}$ ion $(302,317$, $340,350,369,376,483 \mathrm{~nm}$ ) were found on excitation spectra. Instead, for $\lambda_{\mathrm{em}}=495$ and $582 \mathrm{~nm}$, the Dy ${ }^{3+}$ lines $(323,348,362,387 \mathrm{~nm})$ appeared, and for $\lambda_{\mathrm{em}}=546 \mathrm{~nm}$, the excitation lines characteristic for the $\mathrm{Er}^{3+}$ ion were observed. It is likely that intensive $\mathrm{Er}^{3+}$ emission and excitation lines hide the terbium

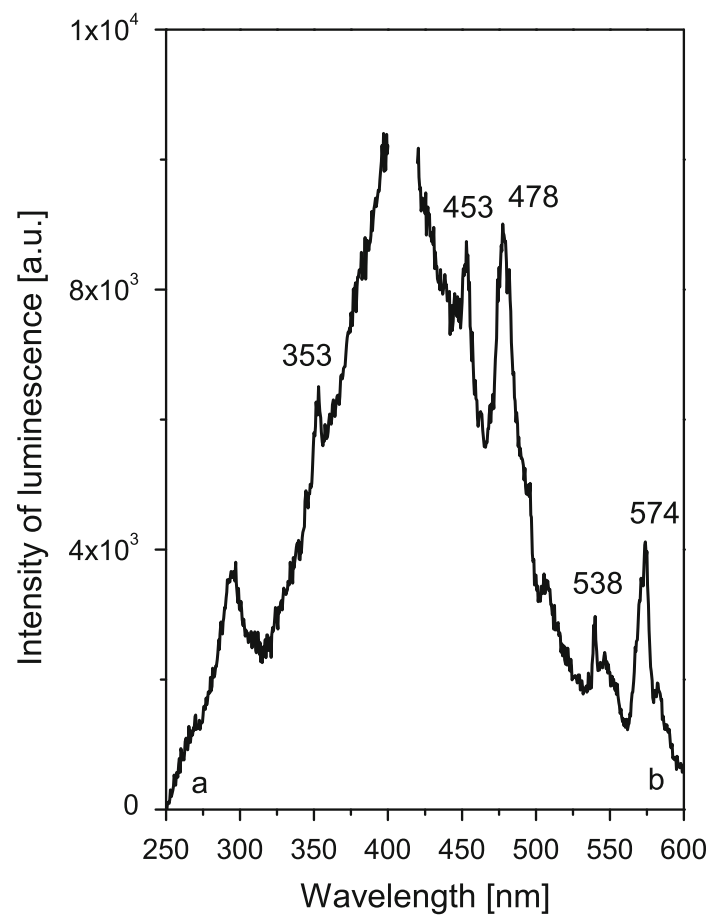

Fig. 7 Luminescence spectra of $\mathrm{Tm}^{3+}: a$ excitation spectrum monitored at $\lambda_{\mathrm{em}}=453 \mathrm{~nm}, b$ emission spectrum measured at $\lambda_{\text {exc. }}=353 \mathrm{~nm}$, measured at $\mathrm{T}=300 \mathrm{~K}$

luminescence. Moreover, the complex nature of the $478 \mathrm{~nm}$ emission line of $\mathrm{Dy}^{3+}$ ion could be seen for other crystals (Bodył-Gajowska 2010).

The $\mathrm{Tm}^{3+}$ luminescence for minerals was measured mainly using the time-resolved method (Gaft et al. 2005) or by the cathodoluminescence (CL) technique. In this study, we demonstrate the evident emission of thulium ion (Fig. 7); when $\lambda_{\text {exc. }}=353 \mathrm{~nm}$, the transitions ${ }^{1} \mathrm{D}_{2} \rightarrow{ }^{3} \mathrm{H}_{4}$ of $\mathrm{Tm}^{3+}$ at $453 \mathrm{~nm}$ as well as ${ }^{4} \mathrm{~F}_{9 / 2} \rightarrow{ }^{6} \mathrm{H}_{15 / 2}(478 \mathrm{~nm})$ and $574\left({ }^{4} \mathrm{~F}_{9 / 2} \rightarrow{ }^{6} \mathrm{H}_{13 / 2}\right)$ of $\mathrm{Dy}^{3+}$ ion and ${ }^{4} \mathrm{~S}_{3 / 2} \rightarrow{ }^{4} \mathrm{I}_{15 / 2}$ $(538 \mathrm{~nm})$ of $\mathrm{Er}^{3+}$ ion were observed. The concentration of thulium in our fluorite crystal was rather high, but lower than in the crystal of Aierken et al. (2003), so the obtained spectrum could be deemed a success.

The very intensive luminescence of $\mathrm{Er}^{3+}$ ion in the VIS and NIR part of spectrum is well known. Under $\lambda_{\text {exc. }}=377 \mathrm{~nm}$, strong several lines appear (Fig. 8) and are connected to following electron transitions: $523 \mathrm{~nm}$ to ${ }^{2} \mathrm{H}_{11 / 2} \rightarrow{ }^{4} \mathrm{I}_{15 / 2}$ and 538-554 nm to the ${ }^{4} \mathrm{~S}_{3 / 2} \rightarrow{ }^{4} \mathrm{I}_{15 / 2}$. The NIR emission spectrum of $\mathrm{Er}^{3+}$ was measured at $\lambda_{\text {exc. }}=521 \mathrm{~nm}$ as 978 (974) $\mathrm{nm}$ and 1,529 nm lines, that is, ${ }^{4} \mathrm{I}_{11 / 2} \rightarrow{ }^{4} \mathrm{I}_{15 / 2}$ and ${ }^{4} \mathrm{I}_{13 / 2} \rightarrow{ }^{4} \mathrm{I}_{15 / 2}$ transitions, respectively (Fig. 3). The luminescence lifetime for the excited state of the ${ }^{4} \mathrm{~S}_{3 / 2}$ of $\mathrm{Er}^{3+}$ ion in this fluorite was measured ( $\tau=436 \mu \mathrm{s})$ and was close to that predicted by the JuddOfelt analysis for ${ }^{4} \mathrm{~S}_{3 / 2} \rightarrow{ }^{4} \mathrm{I}_{15 / 2}$ transition of $\mathrm{Er}^{3+}$ ion in 


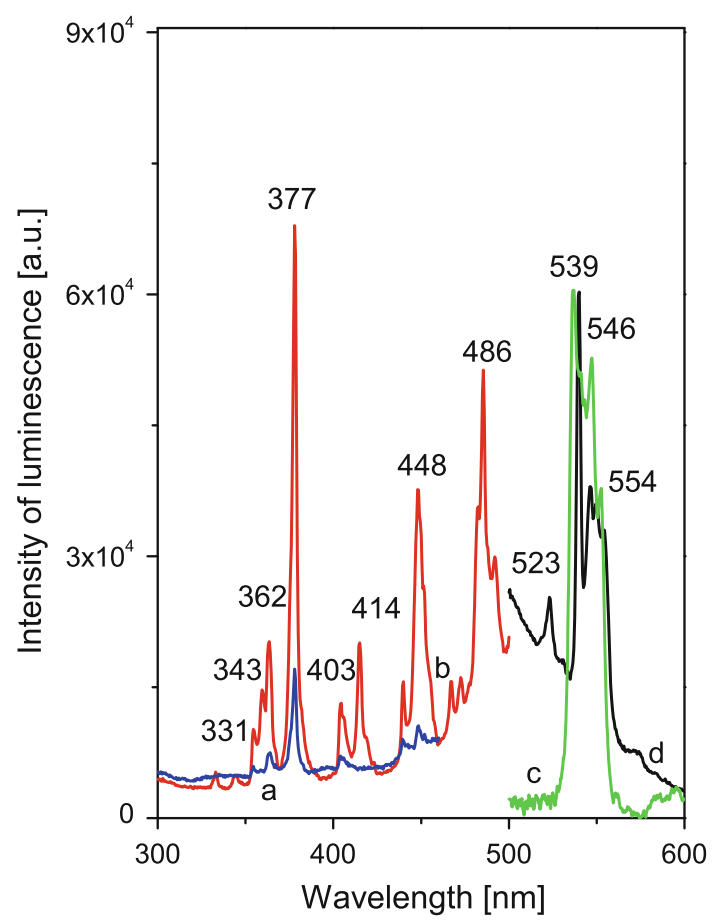

Fig. 8 Luminescence spectra of $\mathrm{Er}^{3+}: a$ and $b$ excitation spectra monitored at $\lambda_{\mathrm{em}}=539$ and $523 \mathrm{~nm}$ (red and blue lines, respectively), $c$ and $d$ emission spectra measured for $\lambda_{\text {exc. }}=415 \mathrm{~nm}$ and for $\lambda_{\text {exc. }}=377 \mathrm{~nm}$, (green and black lines, respectively), all measured at $\mathrm{T}=300 \mathrm{~K}$

phosphate glass (Mazurak et al. 2010). When $\lambda_{\text {exc. }}=415 \mathrm{~nm}$ is used, emission line $523 \mathrm{~nm}$ of the erbium ion disappears almost completely, and the most intensive lines become $536 \mathrm{~nm}$ and $552 \mathrm{~nm}$. With excitation at $415 \mathrm{~nm}(24,096$ $\left.\mathrm{cm}^{-1}\right)$, the ${ }^{2} \mathrm{H}_{11 / 2}$ at $523 \mathrm{~nm}\left(19,120 \mathrm{~cm}^{-1}\right)$ is some 5,000 $\mathrm{cm}^{-1}$ lower in energy and this gap is too large for a phononassisted decay. However, the $\mathrm{Er}^{3+}$ levels nearest to $415 \mathrm{~nm}$ are ${ }^{4} \mathrm{~F}_{3 / 2}$ and ${ }^{4} \mathrm{~F}_{5 / 2}$ at $\sim 22,300 \mathrm{~cm}^{-1}$ (448 nm), and these can be easily populated as there are few phonons below the pump. It is possible to populate the ${ }^{4} \mathrm{~S}_{3 / 2}$ level via energy exchange mechanisms even for weakly coupled $\mathrm{Er}^{3+}$ ions. As a result, an efficient emission is observed from ${ }^{4} \mathrm{~S}_{3 / 2}$, not ${ }^{2} \mathrm{H}_{11 / 2}$.

The comparison of the emission spectrum of fluorite with spectra of phosphate glasses doped with $\mathrm{Er}^{3+}$ and $\mathrm{Ho}^{3+}$ (Fig. 9) allows us to conclude that $\lambda_{\text {exc. }}=415 \mathrm{~nm}$ evidently enhances the green luminescence of $\mathrm{Ho}^{3+}$ ions, that is, the ${ }^{5} S_{2} \rightarrow{ }^{5} I_{8}$ transition. Aierken et al. (2003) have indicated that the emission line at $553 \mathrm{~nm}$ is also characteristic for the ${ }^{5} \mathrm{~S}_{2} \rightarrow{ }^{5} \mathrm{I}_{8}$ transition in the $\mathrm{Ho}^{3+}$ ion.

The comparison of results for steady-state measurements was put together in Table 2 .

Time-resolved measurements

In order to properly identify the origin of emission lines in the 539-554 nm part of the spectrum, to assign them to

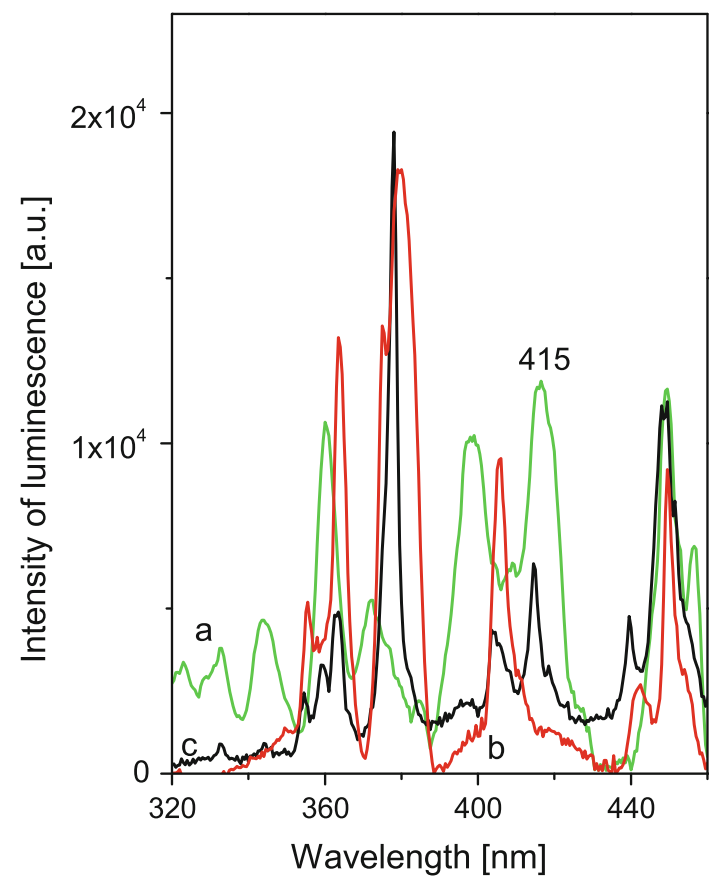

Fig. 9 Excitation spectra of $a \mathrm{Ho}^{3+}$ doped phosphate glass (green line) and $b \mathrm{Er}^{3+}$ doped phosphate glass (red line) monitored $\lambda_{\mathrm{em}}=552 \mathrm{~nm}, c$ of fluorite Paszowice monitored $\lambda_{\mathrm{em}}=550 \mathrm{~nm}$ black line), measured at $\mathrm{T}=300 \mathrm{~K}$

$\mathrm{Er}^{3+}$ or $\mathrm{Ho}^{3+}$ ions, and also to determine the crystal sites occupied by these ions in fluorite lattice, time-resolved measurements were performed. The lifetimes for $\mathrm{Ho}^{3+}$ $540 \mathrm{~nm}$ and $\mathrm{Er}^{3+} 545 \mathrm{~nm}$ emissions measured by Gaft et al. (2001a, b) are similar and equal $5 \mu$ s and $23 \mu \mathrm{s}$, respectively. When the delay time is $10 \mu \mathrm{s}$ and the gate width $10 \mu \mathrm{s}$, the emission of $\mathrm{Ho}^{3+}$ will be observed as well, while the $\mathrm{Er}^{3+}$ center is still in the excited state during the time of measurement and does not participate in the emission. By contrast, for delay time $10 \mu$ s and gate width $30 \mu \mathrm{s}$, the emission of $\mathrm{Ho}^{3+}$ will be already quenched, while the emission of $\mathrm{Er}^{3+}$ will remain.

On the time-resolved emission spectra, it is normal for the most intensive Stark multiplets to appear. The crystal field can split the energy levels of the RE ion and remove their degeneracy, as the complex character of absorption and emission spectra have often revealed. The number of multiplets, commonly referred to as Stark levels, depends on the quantum number $\mathrm{J}$ of ${ }^{2 \mathrm{~S}+1} \mathrm{~L}_{\mathrm{J}}$ terms and on the crystal site symmetry of the ion. The emission lines belong to transitions between Stark's multiplets of excited and ground levels. The ground level is usually named $\mathrm{Z}$, and the excited levels are designated as "Y, A, B, D, E", etc. According to these designations, the ${ }^{5} \mathrm{~F}_{4},{ }^{5} \mathrm{~S}_{2}$ levels of $\mathrm{Ho}^{3+}$ and ${ }^{5} \mathrm{~S}_{3 / 2}$ level of $\mathrm{Er}^{3+}$ are designated as $\mathrm{E}$. The degeneracy of the ground level of $\mathrm{Ho}^{3+}\left({ }^{5} \mathrm{I}_{8}\right)$ and of excited ${ }^{5} \mathrm{~F}_{4},{ }^{5} \mathrm{~S}_{2}$ levels for the tetragonal symmetry site $C_{4 v}$ amount to 13 
Table 2 The most convenient conditions for steady-state measurements of some RE ions; excitation and emission lines and electronic transitions

\begin{tabular}{|c|c|c|c|}
\hline$\lambda_{\mathrm{exc}}[\mathrm{nm}]$ & Ion: emission line (s) [nm]: transition $(\mathrm{s})$ & $\lambda_{\mathrm{em}}[\mathrm{nm}]$ & Excitation line (s) \\
\hline 302 & 336: $\mathrm{Ce}^{3+}: 5 \mathrm{~d}\left(\mathrm{E}_{\mathrm{g}}\right) \rightarrow 4 \mathrm{f}\left({ }^{2} \mathrm{~F}_{7 / 2}\right)$ & 336 & 302: $\mathrm{Ce}^{3+}$ \\
\hline 485 & $\begin{array}{l}\mathrm{Sm}^{2+}: 683,699,730,761,793: \\
{ }^{5} \mathrm{D}_{0} \rightarrow{ }^{7} \mathrm{~F}_{\mathrm{J}}(\mathrm{J}=0,1,2,3,4)\end{array}$ & 682 & $365,452,467,485,494$ \\
\hline 521 & $\begin{array}{l}\mathrm{Nd}^{3+}: 864:{ }^{4} \mathrm{~F}_{3 / 2} \rightarrow{ }^{4} \mathrm{I}_{9 / 2}, 1065:{ }^{4} \mathrm{~F}_{3 / 2} \rightarrow{ }^{4} \mathrm{I}_{11 / 2} \\
\mathrm{Yb}^{3+}: 978:{ }^{4} \mathrm{~F}_{5 / 2} \rightarrow{ }^{2} \mathrm{~F}_{7 / 2} \\
\mathrm{Er}^{3+}: 1529:{ }^{4} \mathrm{I}_{13 / 2} \rightarrow{ }^{4} \mathrm{I}_{15 / 2}\end{array}$ & - & Not measured \\
\hline 442 & $\begin{array}{l}\mathrm{Sm}^{3+}: 598,607,614:{ }^{4} \mathrm{G}_{5 / 2} \rightarrow{ }^{6} \mathrm{H}_{7 / 2} \\
\quad \operatorname{Pr}^{3+}: 641:{ }^{3} \mathrm{P}_{0} \rightarrow{ }^{3} \mathrm{~F}_{2}\end{array}$ & $\begin{array}{l}614 \\
641\end{array}$ & $\begin{array}{l}442,466,479,490 \\
442,466,479,490,398\end{array}$ \\
\hline 399 & $\begin{array}{l}\mathrm{Sm}^{3+}: 560{ }^{4} \mathrm{G}_{5 / 2} \rightarrow{ }^{6} \mathrm{H}_{5 / 2}, 596,606:{ }^{4} \mathrm{G}_{5 / 2} \rightarrow \\
{ }^{6} \mathrm{H}_{7 / 2}, 644,653:{ }^{4} \mathrm{G}_{5 / 2} \rightarrow{ }^{6} \mathrm{H}_{9 / 2} ; \\
\mathrm{Er}^{3+}: 538:{ }^{4} \mathrm{~S}_{3 / 2} \rightarrow{ }^{4} \mathrm{I}_{15 / 2}, 653:{ }^{4} \mathrm{~F}_{9 / 2} \rightarrow{ }^{4} \mathrm{I}_{15 / 2} \\
\mathrm{Dy}^{3+}: 574:{ }^{4} \mathrm{~F}_{9 / 2} \rightarrow{ }^{6} \mathrm{H}_{13 / 2}\end{array}$ & $\begin{array}{l}606 \\
653\end{array}$ & $\begin{array}{l}363,378,399,442 \\
451,466,473,480,363,377 \\
399,440,449,461,467,473,486\end{array}$ \\
\hline 348 & $\begin{aligned} \mathrm{Dy}^{3+}: & 478:{ }^{4} \mathrm{~F}_{9 / 2} \rightarrow{ }^{6} \mathrm{H}_{15 / 2} \\
574: & { }^{4} \mathrm{~F}_{9 / 2} \rightarrow{ }^{6} \mathrm{H}_{13 / 2}\end{aligned}$ & $\begin{array}{l}478 \\
574\end{array}$ & $323,348,362,387,449$ \\
\hline 353 & $\begin{array}{l}\mathrm{Tm}^{3+}: 453:{ }^{1} \mathrm{D}_{2} \rightarrow{ }^{3} \mathrm{H}_{4} \\
\mathrm{Dy}^{3+}: 478:{ }^{4} \mathrm{~F}_{9 / 2} \rightarrow{ }^{6} \mathrm{H}_{15 / 2} \\
574:{ }^{4} \mathrm{~F}_{9 / 2} \rightarrow{ }^{6} \mathrm{H}_{13 / 2} \\
\mathrm{Er}^{3+}: 538:{ }^{4} \mathrm{~S}_{3 / 2} \rightarrow{ }^{4} \mathrm{I}_{15 / 2}\end{array}$ & 453 & 352 \\
\hline 377 & $\begin{array}{l}\mathrm{Er}^{3+}: 523:{ }^{2} \mathrm{H}_{11 / 2} \rightarrow{ }^{4} \mathrm{I}_{15 / 2} \\
\quad 539,546,549,554: \\
{ }^{4} \mathrm{~S}_{3 / 2} \rightarrow{ }^{4} \mathrm{I}_{15 / 2}\end{array}$ & $\begin{array}{l}523,539 \\
546,549 \\
554\end{array}$ & $331,343,362,377,403,414,448,486$ \\
\hline 485 (laser) & $\begin{array}{l}\mathrm{Er}^{3+}: 520:{ }^{2} \mathrm{H}_{11 / 2} \rightarrow{ }^{4} \mathrm{I}_{15 / 2} 535,542,547,550: \\
{ }^{4} \mathrm{~S}_{3 / 2} \rightarrow{ }^{4} \mathrm{I}_{15 / 2} \\
666:{ }^{4} \mathrm{~F}_{9 / 2} \rightarrow{ }^{4} \mathrm{I}_{15 / 2} \\
\mathrm{Sm}^{3+}: 594,604:{ }^{4} \mathrm{G}_{5 / 2} \rightarrow{ }^{6} \mathrm{H}_{7 / 2}, 650:{ }^{4} \mathrm{G}_{5 / 2} \rightarrow{ }^{6} \mathrm{H}_{9 / 2}\end{array}$ & - & Not measured \\
\hline 270 (laser) & $\begin{array}{l}\mathrm{Nd}^{3+}: 850:{ }^{4} \mathrm{~F}_{3 / 2} \rightarrow{ }^{4} \mathrm{I}_{9 / 2}, 1047,1065:{ }^{4} \mathrm{~F}_{3 / 2} \rightarrow{ }^{4} \mathrm{I}_{11 / 2} \\
\mathrm{Yb}^{3+}: 978:{ }^{4} \mathrm{~F}_{5 / 2} \rightarrow{ }^{2} \mathrm{~F}_{7 / 2}, \\
\mathrm{Er}^{3+}: 974:{ }^{4} \mathrm{I}_{11 / 2} \rightarrow{ }^{4} \mathrm{I}_{15 / 2}, 1529:{ }^{4} \mathrm{I}_{13 / 2} \rightarrow{ }^{4} \mathrm{I}_{15 / 2}\end{array}$ & - & Not measured \\
\hline
\end{tabular}

and 11 , while for the trigonal symmetry site $C_{3 v}-11$ and 9 . The degeneracy of the excited level for the $\mathrm{Er}^{3+}$ ion is double and of ground level it is eightfold, for both symmetry sites.

For low-temperature measurements, the separation of holmium from erbium emission lines was perfectly visible. These lines are shown on Fig. 10a, b for holmium $\left({ }^{5} \mathrm{~F}_{4},{ }^{5} \mathrm{~S}_{2} \rightarrow{ }^{5} \mathrm{I}_{8}\right)$ and erbium ${ }^{4} \mathrm{~S}_{3 / 2} \rightarrow{ }^{4} \mathrm{I}_{15 / 2}$ transitions, respectively. All of these transitions are numbered, counted in $\left[\mathrm{cm}^{-1}\right]$ and shown in Table 3 . The emission lines measured for the fluorite from Paszowice are different from those measured for synthetic crystals by Rector et al. (1966), Dieke (1968), Tallant and Wright (1975), Seelbinder and Wright (1979) or Mujaji et al. (1992). After Seelbinder and Wright (1979) or Mujaji et al. (1992), the most intensive emission lines of the $\mathrm{Ho}^{3+}$ ion in the $C_{4 v}$ symmetry site were measured at $18,606,18,490$ and $18,448 \mathrm{~cm}^{-1}$ and identified as $E_{1}-Z_{1}$, $\mathrm{E}_{1}-\mathrm{Z}_{4}$ and $\mathrm{E}_{1}-\mathrm{Z}_{6}$ transitions, respectively, while for the $C_{3 v}$ symmetry site, the most intensive emission lines and transitions were $18,566 \mathrm{~cm}^{-1}\left(\mathrm{E}_{1}-\mathrm{Z}_{1}\right) \mathrm{cm}^{-1}, 18,539 \mathrm{~cm}^{-1}\left(\mathrm{E}_{1}-\mathrm{Z}_{2}\right)$, and $18,501 \mathrm{~cm}^{-1}\left(\mathrm{E}_{1}-\mathrm{Z}_{3}\right)$. According to Rector et al. (1966) and Tallant and Wright (1975), the most intensive emission lines of $\mathrm{Er}^{3+}$ ion in $C_{4 v}$ symmetry site were measured at 18,622, 18,601,18,539,18,518 and $18,136 \mathrm{~cm}^{-1}$ and identified as $E_{2}-Z_{1}, E_{2}-Z_{2}, E_{1}-Z_{1}, E_{1}-Z_{2}$ and $E_{1}-Z_{6}$ transitions, respectively, while for the $C_{3 v}$ symmetry site, the most intensive emission lines and transitions were at $18,607 \mathrm{~cm}^{-1}$ $\left(E_{2}-Z_{1}\right) \mathrm{cm}^{-1}, 18,591 \mathrm{~cm}^{-1}\left(E_{1}-Z_{1}\right), 18,547 \mathrm{~cm}^{-1}\left(E_{1}-Z_{2}\right)$, $18,364 \mathrm{~cm}^{-1}\left(\mathrm{E}_{1}-\mathrm{Z}_{3}\right)$ and $18,319 \mathrm{~cm}^{-1}\left(\mathrm{E}_{1}-\mathrm{Z}_{5}\right)$.

There were some difficulties with assigning numerous emission lines to luminescence transitions and comparing them to the values of energy, which are known for synthetic $\mathrm{CaF}_{2}: \mathrm{Ho}^{3+}$ or $\mathrm{CaF}_{2}: \mathrm{Er}^{3+}$ crystals. Furthermore, some lines are present on the emission spectrum for holmium ion (Fig. 10a) at the shorter wavelength, whose energy should correspond to the transitions from the higher energy sublevels of ${ }^{5} \mathrm{~F}_{4},{ }^{5} \mathrm{~S}_{2}$ excited level $\left(\mathrm{E}_{11-9}\right)$ to the ground ${ }^{5} \mathrm{I}_{8}$ level $\left(\mathrm{Z}_{1-4}\right)$, according to Mujaji et al. (1992). Because the population of $\left(E_{11-9}\right)$ states at $\mathrm{T}=10 \mathrm{~K}$ is very small, this assumption should be 


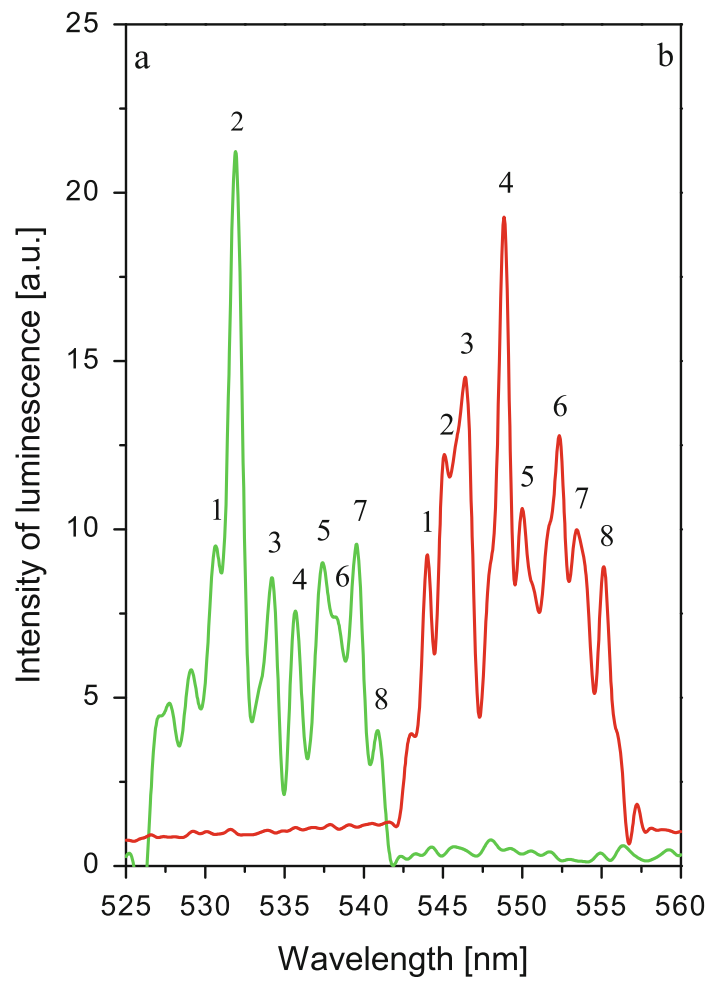

Fig. 10 Time-resolved luminescence spectra of fluorite from Paszowice measured at $\lambda_{\text {exc. }}=415 \mathrm{~nm} ; a$ emission lines of $\mathrm{Ho}^{3+}$ : delay time $=10 \mu \mathrm{s}$, gate time $=10 \mu \mathrm{s}$ (green line $), b$ emission lines of $\mathrm{Er}^{3+}$ : delay time $=10 \mu \mathrm{s}$, gate time $=30 \mu \mathrm{s}($ red line $)$, measured at $10 \mathrm{~K}$

rejected. The above discrepancies have led us to accept the assumption that the energies of excited states of $\mathrm{Ho}^{3+}$ and $\mathrm{Er}^{3+}$ ions in natural crystals are differentinsensibly but measurably-from the energies of excited levels in synthetic crystals. The reason for these differences is the different value of local crystal field strength, due to the more complicated chemical composition of a natural fluorite crystal as compared to its synthetic counterpart.

For the $\mathrm{Ho}^{3+}$ ion in the fluorite from Paszowice, we have assumed that:

- The excited levels ${ }^{5} \mathrm{~F}_{4}$ and ${ }^{5} \mathrm{~S}_{2}$ are energetically separated, and besides the emission from the ${ }^{5} \mathrm{~F}_{4}$ level, the emission from the ${ }^{5} \mathrm{~S}_{2}$ level was measured as well, as was shown for a few other crystals: YSGG (Pugh et al. 1997), $\mathrm{KGd}\left(\mathrm{WO}_{4}\right)_{2}$ (Pujol et al. 2001), $\mathrm{GdLiF}_{4}$, $\mathrm{YLiF}_{4}$ and $\mathrm{LuLiF}_{4}$ (Walsh et al. 2005), YAG (Walsh et al. 2006), YAB (Baraldi et al. 2007) or YGG (Gruber et al. 2009). The ${ }^{5} \mathrm{~F}_{4}$ and ${ }^{5} \mathrm{~S}_{4}$ levels were usually separated in them by an interval of $210-300 \mathrm{~cm}^{-1}$;

- The splitting of ground ${ }^{5} \mathrm{I}_{8}$ level $(\Delta \mathrm{Z})$ and excited level ${ }^{5} \mathrm{~S}_{2}(\Delta \mathrm{E})$ is different in this case than for a synthetic $\mathrm{CaF}_{2}: \mathrm{Ho}^{3+}$ crystal;
- Similarly to a synthetic $\mathrm{CaF}_{2}: \mathrm{Ho}^{3+}$ crystal, the most intensive transitions for a holmium ion in a tetragonal site should be $E_{1}-Z_{1}$ and $E_{1}-Z_{4}$, but for a trigonal site, they could also be $E_{1}-Z_{1}$ and $E_{1}-Z_{3}$.

For the $\mathrm{Er}^{3+}$ ion in the fluorite from Paszowice, we have assumed that:

- There are differences in the splitting of the ground ${ }^{4} \mathrm{I}_{15 / 2}$ level $(\Delta \mathrm{Z})$ and the excited level ${ }^{5} \mathrm{~S}_{3 / 2}(\Delta \mathrm{E})$ for our fluorite and synthetic $\mathrm{CaF}_{2}: \mathrm{Er}^{3+}$ crystals;

- the energy of excited level ${ }^{5} \mathrm{~S}_{3 / 2}$ is different (lower) in comparison with a synthetic crystal;

- Similarly to a synthetic $\mathrm{CaF}_{2}: \mathrm{Er}^{3+}$ crystal, the most intensive transition for erbium ion in a tetragonal site should be $E_{2}-Z_{1}, E_{1}-Z_{1}, E_{1}-Z_{2}$ and $E_{1}-Z_{5,6}$, but for trigonal site also $E_{1}-Z_{1}, E_{1}-Z_{2}$ and $E_{1}-Z_{3}$;

- For the $\mathrm{Er}^{3+}$ ion in a $\mathrm{CaF}_{2}$ crystal, the energy of the $\mathrm{Z}_{4}$ level could not be identified.

The above assumptions allow us to make a tentative assignment of luminescence lines to a particular transition of holmium and erbium ions in $C_{3 v}$ and $C_{4 v}$ symmetry sites (Fig. 10; Table 3). The excited level ${ }^{5} \mathrm{~S}_{3 / 2}$ of $\mathrm{Er}^{3+}$ has lower energy by about 320 and $240 \mathrm{~cm}^{-1}$ for $C_{4 v}$ and $C_{3 v}$ sites, respectively, whereas the excited level ${ }^{5} \mathrm{~S}_{2}$ of $\mathrm{Ho}^{3+}$ has higher energy by about 114 and $37 \mathrm{~cm}^{-1}$ for $C_{4 v}$ and $C_{3 v}$ sites, respectively. The splitting of ground level $\left({ }^{4} \mathrm{I}_{15 / 2}\right)$ of the $\mathrm{Er}^{3+}$ ion occupying $C_{4 v}$ and $C_{3 v}$ symmetry sites in synthetic $\mathrm{CaF}_{2}$ is equal to 84 and $16 \mathrm{~cm}^{-1}$, respectively, while the splitting of the excited level ${ }^{5} \mathrm{~S}_{3 / 2}$ equals 452 and $461 \mathrm{~cm}^{-1}$. For the $\mathrm{Ho}^{3+}$ ion in synthetic $\mathrm{CaF}_{2}$, it was found that the splitting of the ground level is equal to 512 and $423 \mathrm{~cm}^{-1}$ for the $C_{4 v}$ and $C_{3 v}$ symmetry sites, respectively, while the splitting of the excited level equals 289 and $206 \mathrm{~cm}^{-1}$. From our tentative assignment, the splitting of the excited level for both ions seemed to be generally lower than in a synthetic crystal.

\section{Summary}

This study has shown that steady-state measurements can identify the $4 \mathrm{f}$ ions in natural crystals. The luminescence of $\mathrm{Pr}^{3+}, \mathrm{Nd}^{3+}$ and $\mathrm{Tm}^{3+}$ ions in fluorite crystal have been received by steady-state measurements; the luminescence of $\mathrm{Ce}^{3+}, \mathrm{Sm}^{2+}, \mathrm{Eu}^{2+}, \mathrm{Sm}^{3+}, \mathrm{Dy}^{3+}, \mathrm{Er}^{3+}$ and $\mathrm{Yb}^{3+}$ was measured as well. In comparison with earlier studies on this subject (e.g. Aierken et al. 2003), the intensive luminescence was measured for concentrations of RE ions 1.5-4.0 times smaller. The fluorite crystal studied in this paper is another example of a fluorite for which the violet luminescence did not dominate. Transitions between energy levels of the $\mathrm{Ho}^{3+}$ and $\mathrm{Er}^{3+}$ ions for a natural fluorite 
Table 3 The energy of transitions between Stark's levels-excited and ground-and assignment to $C_{4 v}$ and $C_{3 v}$ symmetry sites

\begin{tabular}{|c|c|c|c|c|c|c|c|}
\hline \multicolumn{4}{|c|}{ Emission of $\mathrm{Ho}^{3+}$ ion } & \multicolumn{4}{|c|}{ Emission of $\mathrm{Er}^{3+}$ ion } \\
\hline $\begin{array}{l}\text { Number of } \\
\text { emission line } \\
\text { (Fig. 10a) }\end{array}$ & 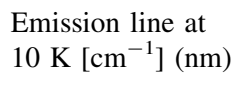 & $\begin{array}{l}\text { Site } \\
\text { symmetry } \\
\mathrm{C}_{4 \mathrm{v}}\end{array}$ & $\begin{array}{l}\text { Site } \\
\text { symmetry } \\
\mathrm{C}_{3 \mathrm{v}}\end{array}$ & $\begin{array}{l}\text { Number of } \\
\text { emission line } \\
\text { (Fig. 10b) }\end{array}$ & $\begin{array}{l}\text { Emission line at } \\
10 \mathrm{~K}\left[\mathrm{~cm}^{-1}\right](\mathrm{nm})\end{array}$ & $\begin{array}{l}\text { Site } \\
\text { symmetry } \\
\mathrm{C}_{4 \mathrm{v}}\end{array}$ & $\begin{array}{l}\text { Site } \\
\text { symmetry } \\
\mathrm{C}_{3 \mathrm{v}}\end{array}$ \\
\hline 1 & $18,843(530.7)$ & \multicolumn{2}{|c|}{${ }^{5} \mathrm{~F}_{4}-{ }^{5} \mathrm{I}_{8}$ or $\mathrm{J}-\mathrm{Y}$} & 1 & $18,386(543.9)$ & - & $\mathrm{E}_{2}-\mathrm{Z}_{1}$ \\
\hline 2 & $18,804(531.8)$ & & & 2 & $18,347(545.0)$ & - & $\mathrm{E}_{1}-\mathrm{Z}_{1}$ \\
\hline 3 & $18,720(534.2)$ & $\mathrm{E}_{1}-\mathrm{Z}_{1}$ & - & 3 & $18,301(546.4)$ & $\mathrm{E}_{2}-\mathrm{Z}_{1}$ & $\mathrm{E}_{2}-\mathrm{Z}_{3}$ \\
\hline 4 & $18,666(535.7)$ & $\mathrm{E}_{1}-\mathrm{Z}_{3}$ & - & 4 & $18,220(548.8)$ & $\mathrm{E}_{1}-\mathrm{Z}_{1}$ & $\mathrm{E}_{1}-\mathrm{Z}_{3}$ \\
\hline 5 & $18,603(537.5)$ & $\mathrm{E}_{1}-\mathrm{Z}_{4}$ & $\mathrm{E}_{1}-\mathrm{Z}_{1}$ & 5 & $18,181(550.0)$ & $\mathrm{E}_{1}-\mathrm{Z}_{2}$ & $\mathrm{E}_{1}-\mathrm{Z}_{5}$ \\
\hline 6 & $18,574(538.4)$ & - & $\mathrm{E}_{1}-\mathrm{Z}_{2}$ & 6 & $18,106(552.3)$ & $\mathrm{E}_{2}-\mathrm{Z}_{2}$ & $\mathrm{E}_{2}-\mathrm{Z}_{6}$ \\
\hline 7 & $18,534(539.5)$ & - & $\mathrm{E}_{1}-\mathrm{Z}_{3}$ & 7 & $18,068(553.5)$ & $\mathrm{E}_{1}-\mathrm{Z}_{5}$ & $\mathrm{E}_{1}-\mathrm{Z}_{6}$ \\
\hline 8 & $18,487(540.9)$ & - & $\mathrm{E}_{1}-\mathrm{Z}_{6}$ & 8 & $18,013(555.1)$ & $\mathrm{E}_{1}-\mathrm{Z}_{6}$ & $\mathrm{E}_{1}-\mathrm{Z}_{7}$ \\
\hline
\end{tabular}

crystal were measured. The discrepancies between the energy of Stark levels of holmium and erbium ions in synthetic and natural crystals could have been caused by differences in crystal field strength of natural and synthetic crystals. In order to remove any doubt regarding the assignment of the emission transitions and to calculate the energy of Stark levels, it is necessary to measure the energy of transitions from other excited levels of $\mathrm{Er}^{3+}$ and $\mathrm{Ho}^{3+}$ to ground state and will be the subject of a separate study.

Open Access This article is distributed under the terms of the Creative Commons Attribution License which permits any use, distribution, and reproduction in any medium, provided the original author(s) and the source are credited.

\section{References}

Aierken S, Lee KH, Kusachi I, Yamashita N (2000) Photoluminescence properties of natural fluorite. J Miner Petrolog Sci 95:228-235

Aierken S, Kusachi I, Yamashita N (2003) Natural fluorite emitting yellow fluorescence under UV light. Phys Chem Miner 30:478-485

Baraldi A, Capelleni R, Mazzera M (2007) Hyperfine interaction in $\mathrm{YAB}: \mathrm{Ho}^{3+}$ : a high-resolution spectroscopy investigation. Phys Rev B 76:165130-165139

Bodył S (2006) Luminescencja jonów REE we fluorytach, (in Polish). Gospodarka Surowcami Mineralnymi 2(3):347-353

Bodył S (2009) Luminescence properties of $\mathrm{Ce}^{3+}$ and $\mathrm{Eu}^{2+}$ in fluorites and apatites. Mineralogia 40(1-4):5-18

Bodył S, Czaja M, Mazurak Z (2009) Optical properties of $\mathrm{Pr}^{3+}$, $\mathrm{Sm}^{3+}$ and $\mathrm{Er}^{3+}$ ions in apatite and phosphate glasses. Phys Proceedia 2(2):515-525

Bodył-Gajowska S (2010) Spektroskopia lantanowców w wybranych minerałach. Dissertation, University of Silesia

Caldino U, de la Cruz C, Munoz H, Rubio O (1989) $\mathrm{Ce}^{3+} \rightarrow \mathrm{Eu}^{2+}$ energy transfer in $\mathrm{CaF}_{2}$. Solid State Commun 69:347-351

Chrysochoos J, Stillman MJ, Jacobs PWM (1982) Laser induced luminescence of $\mathrm{Pr}^{3+}$ in $\mathrm{CaF}_{2}$ attributed to different local site symmetries. In: Silber, Rhyne (eds) The rare earths in modern science and technology, vol. 3 McCarthy. Plenum Publishing Corporation, pp 161-164
Chrysochoos J, Jacobs PWM, Stilman MJ (1983) Laser induced emission spectra of $\mathrm{Pr}^{3+}$ in $\mathrm{CaF}_{2}$ at low temperatures. J Lumin 28:177-190

Czaja M, Bodył S, Głuchowski P, Mazurak Z, Stręk W (2008) Luminescence properties of rare earth ions in fluorite, apatite and scheelite mineral. J Alloys Compd 451:290-292

Dieke J (1968) Spectra and energy levels of rare-earth ions in crystals. Wiley, New York

Elcombe MM, Pryor AW (1970) Lattice dynamics of calcium fluorite. J Phys C3:492-500

Fenn JB, Wright JC, Fong FK (1973) Optical study of ion-defect clustering in $\mathrm{CaF}_{2}: \mathrm{Er}^{3+}$. J Chem Phys 59:5591-5599

Gaft M, Reisfeld R, Panczer G, Blank Ph, Boulon G (1998) Laserinduced time-resolved luminescence of minerals. Spectrochim Acta A 54:2163-2175

Gaft M, Panczer G, Reisfeld R, Uspensky E (2001a) Laser-induced time-resolved luminescence as a tool for rare-earth element identification in minerals. Phys Chem Miner 28:347-363

Gaft M, Reisfeld R, Panczer G, Ioffe O, Segal I (2001b) Laserinduced time-resolved luminescence as means for discrimination of oxidation state of Eu in minerals. J Alloys Compd 323-324: 842-846

Gaft M, Reisfeld R, Panczer G (2005) Luminescence spectroscopy of minerals and materials. Springer, Berlin

Gaft M, Reisfeld R, Panczer G, Dimova M (2008) Time-resolved laser-induced luminescence of UV-vis emission of $\mathrm{Nd}^{3+}$ in fluorite, scheelite and barite. J Alloys Compd 451:56-61

Gruber JB, Burdick GW, Valiev UV, Nash KL, Rakhimov SA, Sardar DK (2009) Energy levels and symmetry assignments for star components of $\mathrm{Ho}^{3+}\left(4 \mathrm{f}^{10}\right)$ in yttrium gallium garnet $\left(\mathrm{Y}_{3} \mathrm{Ga}_{5} \mathrm{O}_{12}\right)$. J Appl Phys 106:113110-113112

Illiev M, Liarokapis E, Sendova MB1 (1988) Laser excited luminescence of rare earth impurities in natural and synthetic $\mathrm{CaF}_{2}$. Phys Chem of Miner 15:597-600

Kirilyuk LV (1973) The concentration dependence of the intensity of the luminescence line at $\lambda=551.2 \mathrm{~nm}$ in single crystals of $\mathrm{CaF}_{2}-\mathrm{Ho}^{3+}$ and $\mathrm{CaF}_{2}-\mathrm{Ho}^{3+} \mathrm{Eu}^{2+}$. Z Prikl Spektr 19(5):843-845

Mazurak Z, Bodył S, Lisiecki R, Gabryś-Pisarska J, Czaja M (2010) Optical properties of $\mathrm{Pr}^{3+}, \mathrm{Sm}^{3+}$ and $\mathrm{Er}^{3+}$ doped $\mathrm{P}_{2} \mathrm{O}_{5}-\mathrm{CaO}-$ SrO-BaO phosphate glass. Opt Mater 32:547-553

Mujaji M, Jones GD, Syme RW (1992) Polarization study and crystalfield analysis of the laser-selective excitation spectra of $\mathrm{Ho}^{3+}$ ions in $\mathrm{CaF}_{2}$ and $\mathrm{SrF}_{2}$ crystals. Phys Rev B 46:14398-14410

Oskam KD, Houtepen AJ, Meijerink A (2002) Site selective 4f5d spectroscopy of $\mathrm{CaF}_{2}: \mathrm{Pr}^{3+}$. J Lumin 97:107-114 
Petit V, Camy P, Doualan JL, Moncorge R (2007) Refined analysis of the luminescent centers in the $\mathrm{Yb}^{3+}: \mathrm{CaF}_{2}$ laser crystal. J Lumin 122-123:5-7

Pugh VJ, Richardson FS, Gruber JB, Seltzer MD (1997) Characterization and analysis of the $4 f$-electronic states of trivalent holmium in yttrium scandium gallium garnet. J Phys Chem Solids 58:85-101

Pujol MC, Cascales C, Rico M, Massons J, Diaz F, Porcher P, Zaldo C (2001) Measurements and crystal field analysis of energy levels of $\mathrm{Ho}^{3+}$ and $\mathrm{Er}^{3+}$ in $\mathrm{KGd}\left(\mathrm{WO}_{4}\right)_{2}$ single crystal. J Alloys Compd 323-324:321-325

Rector CW, Pandey BC, Moos HW (1966) Electron paramagnetic resonance and optical Zeeman spectra of type II $\mathrm{CaF}_{2}: \mathrm{Er}^{3+}$. J Chem Phys 45(1):171-179

Seelbinder MB, Wright JC (1979) Site-selective spectroscopy of $\mathrm{CaF}_{2}: \mathrm{Ho}^{3+}$. Phys Rev B 20:4308-4320

Subramanian U, Mukherjee ML (1987) Thermoluminescence spectra and $\mathrm{X}$-ray luminescence spectra of $\mathrm{CaF}_{2}-\mathrm{Ng}$ single crystals. J Mat Sci 22:473-477
Tallant DR, Wright JC (1975) Selective laser excitation of charge compensated sites in $\mathrm{CaF}_{2}: \mathrm{Er}^{3+}$. J Chem Phys 63:2074-2085

Tofield BC, Weber HP (1974) Efficient phonon-assisted long-lifetime $\mathrm{Nd}^{3+}$ luminescence in $\mathrm{Cs}_{2} \mathrm{NaNdCl}_{6}$. Phys Rev B 10:4560-4567

Walsh BM, Grew GW, Barnes NP (2005) Energy levels and intensity of $\mathrm{Ho}^{3+}$ ions in $\mathrm{GdLiF}_{4}, \mathrm{YLiF}_{4}$ and $\mathrm{LuLiF}_{4}$. J Phys Condens Matter 17:7643-7665

Walsh BM, Grew GW, Barnes NP (2006) Energy levels and intensity parameters of $\mathrm{Ho}^{3+}$ ions in $\mathrm{Y}_{3} \mathrm{Al}_{5} \mathrm{O}_{12}$ and $\mathrm{Lu}_{3} \mathrm{Al}_{5} \mathrm{O}_{12}$. J Phys Chem Solids 67:1567-1582

Weber MJ, Bierig RW (1964) Paramagnetic resonance and relaxation of trivalent rare-earth ions in calcium fluoride. I. Resonance spectra of crystal fields. Phys Rev 234:A1492-A1503

Wood DL, Kaiser W (1962) Absorption and Fluorescence of $\mathrm{Sm}^{2+}$ in $\mathrm{CaF}_{2}, \mathrm{SrF}_{2}$ and $\mathrm{BaF}_{2}$. Phys Rev 126:2079-2088 